\title{
Surgery of very late intrathoracic esophgeal ruptures and perforations
}

\begin{abstract}
Objective: The reasons of delay and a more selective management of 7 unusually late esophageal disruptions is evaluated in this study.

Material and methods: In case of a 13 day-old rupture, left transthoracic debribement, primary repair with hiatusplasty was done. In a 6 week-old postpneumonectomy leak, esophageal exclusion, fenestration, chemotherapy and Roux-en-Y bypass was performed. Closure with serratus anterior flap was used in a small esophageal leak with empyema which occured 4 months after pneumonectomy. In a iatrogenic, 9 day-old esophageal injury, suture, than Urchel type temporary exclusion was carried out. In a 6 week-old iatrogenic leak with localised empyema, Urchel-Ergin type exclusion with thoracostomy was used. As a first step esophageal exclusion and than decortication was performed in a 13 day-old rupture with empyema,followed by substenal colonic bypass 2 months later. In a 7 day-old transfixion esophgeal wound, suture with drainage was performed. The patient with closed esophagus was lost, for irreversibile sepsis. Results. Recovery time was 9 to 28 days.
\end{abstract}

Conclusion: Even in such unique esophageal disruptions individual approach prove to useful.

Keywords: very late esophageal disruptions, reinforced primary repair, closure with temporary exclusion, johnson type exclusion, delayed colonic or roux-en- $\mathrm{y}$ bypass
Volume 7 Issue 6 - 2020

\section{Kotsis, SZ Kostic, PVadász}

Korányi Pulmonological Institute, Department of Thoracic Surgery, Budapest, Hungary

Correspondence: L Kotsis, Korányi Pulmonological Institute, Department of Thoracic Surgery, Budapest, Hungary, Email lkosisdr@gmail.com

Received: October 18, 2020 | Published: November 09, 2020

\section{Introduction}

Once the diagnosis of esophageal leak is made the most critical decision is the choice of the most appropriate management. The firs choice procedure should be selected on the basis of underlying esophageal disease, the nature, site and magnitude of disruption and the time elapsed after onset of perforation. Although the importance of primary closure of spontaneous esophageal rupture has been accepted, the recurrence rate even in Abboth $^{1}$ or Belsey ${ }^{2}$ series was high. Successful assessment of early and more than 48 hour-old rupture has been published by Symbas, ${ }^{3}$ Finley (4) and Westaby ${ }^{5}$ at the end of 70th decade. A new multimodality approach in such disruptions was presented in 1986, during the 3th World Congress of Esophageal Surgery. ${ }^{6}$ There are two opposite opinion about the delayed assessment of esophageal perforations : primary repair versus primary resection and recently some author advocate stenting. The authors aim is to present the treatment protocol in exceptional late esophageal disruptions.

\section{Material and method}

Forthy six patients with spontaneous rupture or esophageal perforation have been managed (1981-2001) at Thoracic Surgical Clinic of Korány Pulmonological Institute, Budapest, Hungary. We present 7 patients with extremely long delay befor recognition of esophageal injury.

\section{Case I}

A middle age man for retrosternel pain was admitted urgently in intensive care unit. The myocardial infarction has been excluded and drainage of left side pleural fluid with unknow origin was instituted. After 9 days delay the swallow study discovered typical esophageal rupture. At admission the patient was in deep sepsis, allowing only Johnson type esophageal exclusion. 7 days later left side pleural decortication and delayed colonic by-pass (with isoperistaltic left colon) was carried out 2 months later.

\section{Case 2}

In a 6 week-old iatrogenic perforation (by sclerotherapy of Malorry-Weiss bleeding) of a diabetic man, admitted with localised lower rigth side empyema. Urschel- Engin type ${ }^{8,9}$ distal end cervical banding with Petzer tube esophagostomy, gastrostomy and tube thoracostomy for suction lavage was ${ }^{10}$ successful. The bandings were removed 12 days later.

\section{Case 3}

In a small middle third eophageal perforation and subsequent empyema developed 4 months after rigth pneumonectomy for recurrent bronchial tumor, coverage with serratus anterior muscle flap, combined with Schede -type thoracoplasty, proved to be useful. The patien was alive 7 years later ! suffering only to a slight grade gastro-esophageal reflux.

\section{Case 4}

Rigth side pneumothorax developed after inadequat raser blad extraction, folloved by swallov study 5 days later, transferred at 9 days of injury. Thourough rigth thoracotomy, decortication and left cevical approach, the 2 layer closure of a $14 \mathrm{~cm}$ long leak become successful but with a small suture line insufficiency, managed by Urschel type exclusion- diversion. 10 days later the leak closed. The exclusion banding was removed 12 days later. The patient was discharged with closed esophagus and spontaneously closed cervical stoma.

\section{Case 5}

Six weeks after left pneumonectomy with extended lymphadenectomy for bronchial tumor, empyema developed. The first 
step was exclusion of esophageal leak by Johnon- type one, followed by fenestration. Chemotherapy and after-loading irradiation was necessary for conralateral bronchial recurrence and liver metastasis. After failure of presternal skin tube by-pass, a Roux-en -Y presternal successful by-pass was carried out 9 months after onset of perforation.

\section{Case 6}

A middle age women after womiting was hospitalised with left side pleural collection. Considered as empyema, drainage and antibiotics were used.Transferred with 13 days delay, contrast material swallow discovered typical esophageal rupture. Through left thoracic approach, after mediastinal decompression, debridment and decortication, suturet of the viable moucosal edges was combined with hiatal muscle plasty. Unevenful recovery, discharge at 9 days postoperatively.

\section{Case 7}

The precardial punished wound of a 29 age woumen was inadequately explored through antero-lateral thoracotomy. 7 days later the swallow study discovered a transfixion esophageal injury. Although closure through left postero- lateral thoracotomy prouved to be successful at the 7 days swallowing study, the patient was lost for purulent mediastinitis, pericarditis and empyema.

\section{Result}

After removal of Urschel -type exclusion banding, the esophagus was free from stenosis. The cervical stoma had closded spontaneously. The recovery time was between 9-28 days. The swallowing adaptation time of patient who received substernal isoperistaltic colonic bypass was short, only 6 days. After postpneumonectomy esophageal leak closure, the patint was alive 7 years later.

\section{Discussion}

It is generally accepted that the delay of diagnosis is one of the most important factor of high mortalty rate in esophageal perforation. The reason of delay may be attributed to superfitial history, diagnostic failure, inadequate surgical exploration and fals evaluation of the pleural content or of complication of usual esophageal surgical procedure. In late esophageal rupture Symbas ${ }^{3}$ buttressed the primary repair with 180 grade fundoplication. Faced with 3 case of 2 dayold rupture $W^{2}$ stabe $^{5}$ used pedicled diaphragmatic flap for closure reinforcement.In Skinner series, ${ }^{13}$ the overlooked injuries during Belsey-Mark IV hiatal repair, required later multiple reoperations. All patiens suffering mucousal leak during Heller type myotomy for achalasia, were lost. Injurie of the healty esophagus demand a comlpex procedure for salvage of the organ. In spite of the long time elapsed befor surgery, primary reinforced repair may be considered as the preferred method. In such circumstances, through transthoracic approach, debridment and meticulous preparation of the esophageal leak edges, closure with interrupted suture, should be the first step of management. In our experience the strong, well vascularised pedicled diaphragmatic flaps ${ }^{11}$ was the firs line patch procedure for the suture line buttress. Many authors accept that the danger of recurreny may prevent by autologus patch procedure of the closure. The Pailorero concep $^{12}$ abouth the usefullness of extrathoracic muscle flaps has been integrated in the management of esophageal leaks.

If the perforation is associated with concurrent obstructive esophageal disease, or there is an extensive injury, when the reconstruction would result remarcable $(50 \%)$ narrowing of the lumen, if generalised sepsis has alredy developed, primary resection is a safe and reliable treatment option. In case of perforated resectable esophageal carcinoma or in injury of achalasia induced megaesophagus, transhiatal esophageal resection is the best option. ${ }^{7}$ On contrary, conventional transthoracic resection shoud be used for the perforated, long stending, corrosive strictures, when transhiatal approach may produse disastrous intraoperative bleeding. In instances of postpneumonectomy empyema folowing radical resection with extended lymphadenecomy, esophageal injury may always be suspected. In such instances, purulent mediastinitis creates unfavorable condition for high risk esophagectomy. On contrary, esophageal exclusion, combined with tube thoracostomy and subsequent fenestration was well tolerable by our poor risk patients, providing favourable healing condition for empyema.

\section{Conclusion}

Our study focused on same exceptional esophageal disruptions, an individual approach ${ }^{14}$ proved to be usefull for patients salvage and maintenance of the organ.

\section{Acknowledgments}

None.

\section{Funding}

None.

\section{Conflicts of interest}

Authors declare that there is no conflict of interest.

\section{References}

1. Abboth O A, Mansur KA, Logan WD. Atraumatic so-called,,spontaneous” rupture of esophagus. A review of 47 personal cases with comments on a new method of surgical therapy. J Thorac Cardiovasc Surg. 1970:59(1):67-83.

2. Triggiani E, Belsey R. Esophageal trauma: incidense, diagnosis, and management.Thorax. 1977;32(3):241-247.

3. Symbas PN, Hatcher Ch R, Haralfist N. Spontaneous rupture of the esophagus. Ann Surg. 1978;187:634-640.

4. Finley RJ, Pearson G, Weisel RD, et al. The management of nonmalignat intrathoracic esophageal perforation. Ann Thorac Sur. 1980;30(6):578-581.

5. Westaby S, Shepard MP, Nohl-Olser HC. The use of diaphragmatic pedicle grafts for reconstructive procedures in the esophageal and tracheobronchial tree. Ann Thorac Surg. 1982;33(5):486-490.

6. Kotsis L, Csikos M. Horváth ÖP, et al. Multimodality approach to the treatment of the early and late esophageal disruptions and perforations. Springer-Verlag Berlin Heidelberg. 1988;1342-1346.

7. Orringer MB, Stirling MC. Esophagectomy for esophageal disruption. Ann Thorac Surg. 1990;49(1):35-43.

8. Urschel HC, Razzuk MA, Wood RE. Improved management of esophageal perforation: exclusion and diversion in continuity. Ann Surg. 1974;179:587-591.

9. Ergin NA, Wetstein L. Temporary diverting cervical esophagostomy. Surg Gynecol Obstet. 1980;151:97-101.

10. Kotsis L, Szabadi G, Kostic Sz. Successful treatment of a 9-day-old iatrogenic esophageal perforation by suture and Urschel type exclusion. Magy Seb. 1983;36:358-336. 
11. Kotsis L, Agócs L. The effecttivenes of diaphragmatic pedicled grafts in esophageal injuries and wall reconstruction. Eur J Cardio-thorac Surg. 1998;14:218-219.

12. Pailorero PC, Arnold PG, Pichler JM. Intrathoracic transposition of extrathoracic skeletal muscle. $J$ Thorac Cardiovasc Surg. 1983;86:809-815.
13. Skinner DB, Little AG, DeMesster T. Management of esophageal peroration. Am J Surg. 1980;139:760-764.

14. Kotsis 1, Kostic, Sz Zubovics K. Multimodality treament of esophageal disruptions. Chest. 1997;112:1304-1309. 